\title{
STATUS OF THE THREE ASIATIC RHINOCEROS
}

\author{
By E. O. Shebbeare
}

I will begin by admitting how slight is my own first-hand knowledge of the three species except for the great one-horned rhinoceros with which I am, or was, fairly familiar during the thirty years that I spent in Bengal and Assam. Although the little two-horned rhinoceros was still said to exist in the Chittagong forests, while I was there at intervals between 1923 and $1930 \mathrm{I}$ never saw even the tracks of this species until I went to Malaya in 1938. Even there, although I got to know its haunts reasonably well, I only caught two fleeting glimpses of the animal itself. As for the third species, the smaller onehorned rhinoceros, I have never even seen its tracks.

Although I have relied mainly on the information of others, either in published records, correspondence or what I regard as reliable hearsay, I have included such observations of my own as appeared to have any value; in each case I have quoted my authority as far as possible. I should like to take this opportunity of once more thanking my correspondents, especially those who have recently responded so fully to my appeal for up-to-date information. I am also greatly indebted to the very full article on the position of rhinoceros in Burma by W. H. F. Ansell, which appeared in the Bombay Natural History Society's Journal (vol. 47, No. 2, p. 249) in December, 1947.

Five living species of rhinoceros, two African and three Asiatic, formerly regarded as members of a single genus, Rhinoceros, have now been divided into four genera, the Asiatic species being :-

Rhinoceros unicornis, the Great One-horned or Indian.

Rhinoceros sondaicus, the Smaller One-horned or Javan.

Dicerorhinus sumatrensis, the Asiatic Two-horned or Sumatran.

(The two African species which do not concern us here are: Diceros bicornis, the Black, and Ceratotherium simum, the White or Square-lipped.)

Before dealing with the three Asiatic species separately I must mention the animals which inhabited the grass jungles on the Ganges at the north end of the Rajmehal hills until the middle of the last century, because their specific identity is doubtful. Blyth and Jerdon regarded them as belonging to the Javan species but Blanford, writing in 1888 , considered this a mistake and believed them to have been of the Indian species.

R. unicornis, here called the Indian Rhinoceros

Blanford (1888) writes: “It was formerly extensively distributed in the Indian Peninsula," but it is not clear whether 
he is writing of historic times for later he speaks of semifossilized remains found near Madras. It is quite possible that historic records of this rhinoceros in southern India exist, though I have not been able to trace any, I should be most grateful if anyone who has come across such reports would let me know. Apart from such very early records this species has
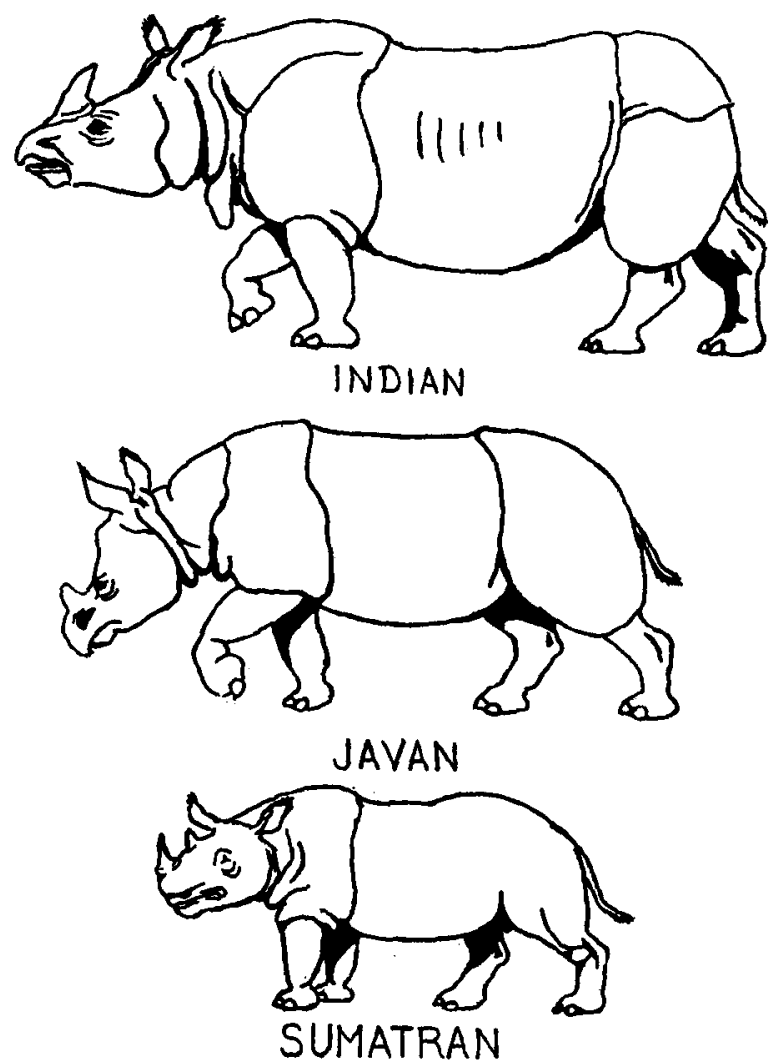

Outline to scale to show the comparative size of the three species.

inhabited the sub-Himalayan tract during historic times, the western limit of its range retreating from Peshawar, in the days of the Emperor Baber (1505-1530), to Rohilkhand (the Barelli district) in the mid-nineteenth century and the Nepal Terai during the present century. The eastern limit of its range has probably remained constant as it is confined by the hills bordering the Brahmaputra gorge. Although its actual range has not been greatly reduced during recent times, its habitat has become 
much restricted in most parts of the range, owing to the encroachment by agriculture-mainly paddy and tea-and the spread of tree-forest into wet savannahs as a result of fireprotection. The country most suitable for this species is tall grass-jungle with patches of savannah and occasional streams and swamps, such is found where the Himalayan rivers after leaving their gorges spread out over a wide tract. This rhinoceros seldom leaves this sort of country to penetrate far into either the hills or the tree-forests which surround it. Though I have once or twice met individuals some miles within the sal-forest, their movements have suggested that they were merely travellers taking the shortest line from one river-bed to another.

I have so far failed to get any very recent estimate of the numbers in the Nepal Terai. E. P. Gee, the best present-day authority on the numbers of this rhinoceros, writes suggesting that, pending a more up-to-date figure from the Nepal Government, we should accept "the old figure of Ripley's". He is referring, I think, to Dr. Dillon Ripley who visited the Nepal Terai to study wild life after the last war, though I am not sure in which year. I understand that this estimate was about fifty animals. I have also heard from E. A. Smythies, who was working in the forests of the Nepal Terai until seven years ago. Although Ripley's figure is the more recent, it is likely that his visit was fairly short - on the other hand, Smythies cautions me that his figure represents the situation when he left and that it may have deteriorated considerably under the new regime. (Another correspondent from Nepal offers the same warning.) Readers must take their choice.

Smythies tells me that the home of the Nepal rhinoceros is the Chitawan Game Reserve, an area of six to eight hundred square miles. This reserve up to 1947 was rigidly and effectively preserved by a force of from one to two hundred specially armed guards and the penalty for killing a rhinoceros was extremely heavy. Cultivation in the tract seemed to be decreasing, if anything, and the inhabitants said the animals were increasing. $\mathrm{He}$ writes: "There were plenty of rhino about; we saw, heard, and bumped into them all over the place." As to numbers, the local guards, who enumerated them periodically, estimated them at between two hundred and three hundred, and the authorities in Kathmandu claimed four hundred.

I am indebted to E. P. Gee for his latest estimate of the numbers surviving in various sanctuaries and reserves in Bengal and Assam. He considers them conservative and more reliable than his earlier figures, published in 1950 . I give both figures :- 


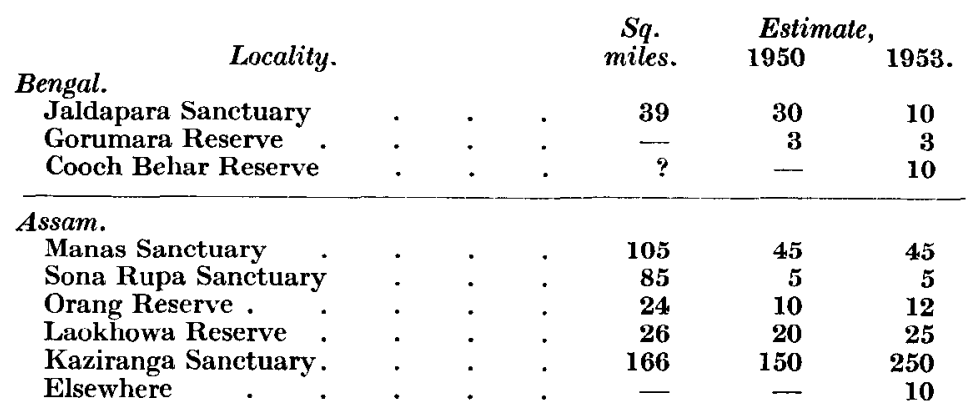

Totals : Bengal, 33 and 23 ; Assam : 230 and 347.

Of Bihar E. P. Gee notes that, though an odd animal strays in from the Nepal Terai, he believes that none stay there. (This, I think, is a reference to reports of rhinoceros from Champaran.)

The estimate of only ten animals in Jaldapara, the largest rhino-sanctuary in Bengal, is distressing ; I have recently had gloomy reports of this area, both from E. P. Gee and H. E. Tyndale, both of whom have visited it since I was last there in 1946. It should be explained that the Cooch Behar rhinoceros country near the Torsa River is continuous with that in Jaldapara and both are now, I understand, included in one forest division.

The case of the Gorumara animals is curious. Ever since 1908 (to my knowledge) a few rhinoceros, never reported as more than three, have inhabited the few patches of grass-jungle which surround the junction of the Jaldhaka and Murti rivers and the Chapramari bhil-a pond a few miles to the north which seldom dries completely. This is a tiny enclave of rhino-country, not much more than a square mile in all, which has been completely shut in by forest since the adjoining savannahs filled up with tree-growth at the beginning of this century. Here the rhinoceros population seems hardly to have varied in nearly fifty years, although on at least two occasions, at long intervals, the tracks of a calf have been associated with others. What is perhaps the most remarkable item of news about this little community has just reached me. No less than twice since I visited the area in $\mathbf{1 9 4 6}$ the carcases of mature animals, apparently uninjured, have been found outside the forest and a few miles from Gorumara ; the last was that of a very old bull. Yet, my informant assures me, there still appear to be two or three rhinoceros in their old haunts. Similar cases of rhinoceros cut off in patches of grass or canebrakes by encroaching trees have occurred, especially in large, continuous blocks of reserved forest. Those I have known were all solitary animals which, 
after being met with at intervals over many years, eventually disappeared.

\section{$\boldsymbol{R}$. Sondaicus here called the Javan Rhinoceros.}

Some points about the past distribution of this species in the northern parts of its range are in doubt. The doubt as to whether the Rajmehal animals belonged to the Javan or the Indian species has already been mentioned. There is also the question of what exactly Sterndale meant by " the western Provinces of China". Ansell apparently takes this to mean Indo-China, and this seems probable. Ansell also puts a query against "Assam", though Blanford includes Assam in its habitat and $\mathrm{I}$ think the general view is that it was formerly found there, at any rate south of the Brahmaputra. In Bengal the records are rather more precise. It certainly occurred in the mangrove forests of the Sundarbans up to the turn of the century when an officer of the Survey Department was reported to have seen either the animal or its tracks. This was, I believe, the last record from the Sundarbans. Shortly afterwards, these forests came under more intensive working when tracks in any part of the area, about four thousand square miles, could hardly have escaped notice-there had been no recent report when I first worked there in 1906. According to Blanford it was still found in parts of eastern Bengal when he wrote in 1888 . He also records an undoubted specimen shot by Kinloch in the Sikkim Terai. Though Blanford gives no date for this I understand it was about 1870 ; if the Rajmehal animals are excluded this must be the most westerly record for the Javan rhinoceros, for I understand that it has not been recorded from the adjoining Nepal Terai.

The most recent report of this species in northern Bengal was early in the present century, by J. W. A. Grieve in the Buxa Forest Division-probably in what is now the Jaldapara Sanctuary. It was shot in mistake for the Indian rhinoceros but the trophies, sent to Messrs. Rowland Ward for preservation, were at once recognized as being those of the Javan species. This firm told me recently that all their old records were unfortunately destroyed during an air-raid.

Once probably fairly plentiful in several parts of Burma, this rhinoceros was realized as being in danger of becoming very rare early in the present century. But it was not until about 1927, partly as a result of the activities of Siamese poachers near the Sittang river, that the Forest Department became seriously alarmed and decided that special measures would be necessary if the species was to be saved from extinction. These 
measures included the formation, about 1928, of a sanctuary some sixty-two square miles in area designed to protect the survivors of the Javan rhinoceros in Burma; this was known as the Kahilu Sanctuary. Unfortunately it was established too late. A through investigation of this sanctuary conducted in $\mathbf{1 9 3 8}$ by the late Theodore Hubback, showed that some at least of the rhinoceros inhabiting the Kahilu belonged to the Sumatran (two-horned) species and everything pointed to the conclusion that the Javan rhinoceros in Burma was extinct.

A year or two earlier, after prolonged search throughout the Malay peninsula by himself and others, Theodore Hubback had come to the conclusion that the Javan species here was represented by a single specimen living in a swampy tract known as Ulu Bernam. As Chief Game Warden he ordered this last survivor to be shot for the careful preservation of all its parts in an American Museum. This decision has often been criticized but, granted that he was right in supposing that no possible mate existed in the locality, and subsequent search proves that he was, it was probably more in the interest of science to make sure that the carcase of such a rare animal was used to the best advantage than to preserve a creature incapable of perpetuating its kind. Although the Ulu Bernam animal was no doubt the last of its species within range of mating, this does not absolutely rule out the possibility of the survival of the Javan rhinoceros in remote parts of the peninsula though this is perhaps unlikely. There are still some inaccessible tracts in Malaya which have not been fully explored and reports of tracks thought to be too large to be those of the Sumatran rhinoceros continue to raise hopes from time to time, hitherto inconclusively.

Blanford says that, in the past, the Javan rhinoceros was also found in Borneo and Sumatra, though Ansell queries the latter, and $I$ can find no information about the localities they inhabited or the date at which they became extinct on either island.

To-day the Udjung Kolon sanctuary at the western extremity of Java is the main, probably the only, place where this species exists. E. P. Gee has kindly passed on information given him by the two men best qualified to speak of the present status of the Javan rhinoceros in this sanctuary, A. Hoogerwerf and P. Ryhiner. The former says that he thinks there are enough to survive for a long while, provided that they are guarded as they are at present. He thinks that perhaps fifteen or twenty were killed after the war, but that now poaching has been stopped. P. Ryhiner estimated the number now in the sanctuary as "not less than thirty nor more than fifty". 
Though this rhinoceros, sometimes at any rate, inhabits country similar to that of the Indian rhinoceros, it seems to use, or have used, tree-forest more. It is said also to have penetrated much farther into the hills, for Sterndale has a record of one at 4,000 feet. (Rightly or wrongly I have not included Blanford's record of one seen in 1887 by Major Macgregor at 7,000 feet to the south-east of Sadiya, because the locality suggest the possibility of confusion with the Sumatran species.)

\section{DICERORHINUS SUMATRENSIS, HERE CALLED THE Sumatran Rhinoceros}

Up to comparatively recent times, say the end of the last century, the range of this species extended, through hilly tracts, from Assam, through Tippera and the Chittagong hill tracts to Arakan to Burma proper and thence to French Indo-China, Siam, Malaya, Sumatra and Borneo, but not to Java. Blanford says it was rare in Assam in $\mathbf{1 8 8 8}$ but records one from the Sankos River (the boundary between Assam and Bengal) in $\mathbf{1 8 7 5}$, and another from Tippera in $\mathbf{1 8 7 7 .}$

From how much of its original range this rhinoceros has now disappeared it is very difficult to say. E. P. Gee tells me that there are none left in India though one or two may still exist in the new Tirap Frontier up the Dihing River. In this connection a curious item of news appeared in the Daily Telegraph for 1st September last, it read :-

"A two-horned rhinoceros, a species believed to exist only in Africa, was seen in North-Eastern Assam." The Associated Press News Agency, who were responsible for this item, were unable to furnish any further details.

F. P. Gee also writes that he can get no information about the Chittagong hill tracts which is now in Pakistan. However, Ansell's map illustrating his note on the position of rhinoceros in Burma, shows entries dated as late as 1945 in the adjoining Arakan Yoma, with an arrow pointing into these hill tracts, which lay outside the area he dealt with. Ansell's map shows similar arrows pointing into Siam where it adjoins the Tennasserim border ; this is the only information on Siam that $I$ have been able to get. Later, when discussing the numbers which may still exist, I have dealt rather more fully with Burma, Malaya, and Sumatra. I have no information about Borneo or Indo-China.

Of the three Asiatic species this is the one whose numbers are the most difficult to estimate. Its grazing grounds straggle over a wide area, often following the ridges, for it is far more of a mountaineer and forest dweller than even the Javan rhinoceros 
is said to be and ridge-paths are its chief highways. To find an Indian rhinoceros in seas of high grass may be difficult but if one has an elephant never impossible ; when crossing a riverbed or feeding on new grass after a burn, they may often be watched on foot or even from the veranda of a bungalow. To find the Sumatran rhinoceros in the tangled tree-forest which clothes the precipitous country in which it spends much of its time, is like looking for a needle in a haystack. Apart from chance encounters, almost the only opportunities it offers an observer are its visits to wallows or salt-licks. The Indian rhinoceros often follows paths used by men and, though not aggressive, is neither shy nor particularly alert. The Sumatran species is both, and the ridge-paths it uses are mostly below about 4,000 feet. It lives therefore mainly within the territory of the river-folk whose ways tend to follow watercourses rather than ridges. Added to the above difficulties in observing this animal properly, almost the whole of its range has lain for the past twelve years within the sphere of hostile operations of one sort or another.

No comprehensive estimate of the numbers of this rhinoceros throughout its range in possible for I have no information about Indo-China or Siam and no estimate for Malaya. Indeed, in the face of difficulties in observation and uncertainty about its survival in certain localities, I had a mind to avoid figures altogether-for figures can give to a guess a reliable appearance which it does not deserve. I cannot, however, omit P. Ryhiner's recent figure of about thirty animals in Sumatra or Ansell's conscientious attempt to arrive at a reasonable figure for Burma in 1947. He has, in fact, given two figures for each locality, the former he calls the "lowest reasonable estimate" $(a)$, and the latter a " possible reasonable estimate" $(b)$ :-

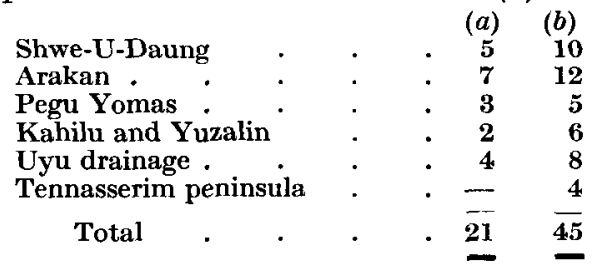

What most people will be concerned to know is the extent to which this rhinoceros has been affected by the war and subsequent unrest in its habitat. I have no information from Burma more recent than Ansell's account and none from Sumatra beyond Ryhiner's estimate. In most of its range, I think, Japanese occupation was followed by banditry; perhaps 
experience in Malaya, of which several Game Wardens have first-hand knowledge, may serve to give an idea of what happened elsewhere. During the actual occupation game of all sorts appeared tamer and, perhaps for this reason, more plentiful. This was the experience of G. R. Leonard who, as a game warden, had charge of the National Park and was dropped back into it as a parachutist. No doubt the death-penalty for carrying fire-arms protected game, though this may have been offset to some extent by the hunger of the population. The bandit stage has been, on the face of it, a far more perilous time for this rhinoceros. Direct evidence is hard to come by because of security measures, shortage of funds and, perhaps most of all, time spent in traversing paths which in peacetime used to be kept clear.

The extent to which the gloomy views that have been expressed are justified is hard to say. The recently retired Chief Game Warden, A. H. Fetherstonhaugh, writes that his personal belief is that rhinoceros have decreased alarmingly but points out how difficult any proper investigation is in present circumstances. A painstaking effort which he has made to tabulate pre-war and post-war observations of this rhinoceros in twentytwo localities is difficult to interpret. On the whole it shows a decline, but this might be attributable partly to animals changing their habitual localities owing to military operations, bandit activity and especially bombing, which he believes has been responsible for some unexpected movements by rhinoceros and elephants recently.

\section{The Future}

The whole question of the survival of all three species appears gloomy. I believe that the increase in firearms is a far more serious threat than the reduction in cover, a menace which has, we hope, passed its peak and which, in any case, is a danger to the Indian species rather than the other two. Any animal condemned to carry a horn worth half its weight in gold and whose blood, urine and other parts are believed to have magic properties is bound to be a target for poachers as long as superstition survives.

On the other hand what the late Government did in Nepal and the present Governments are doing in Assam and Java is open to any stable administration possessing rhinoceros and determined to do it-but not by merely passing laws. The importance of the man on the spot is shown by what Milroy did in the Manas in the twenties and Dent in Jaldapara in the thirties of this century. 